\title{
A MORFOLOGIA DAS VERTENTES E SUA INFLUÊNCIA NOS FENÔMENOS DE ENXURRADA: ALTO CURSO DA BACIA HIDROGRÁFICA DO ANIL SÃO LUÍS- MA
}

\author{
Ismaylli Rafael dos Santos Costa ${ }^{(a)}$, Quésia Duarte da Silva ${ }^{(b)}$, Estevânia Cruz Teixeira ${ }^{(\mathrm{c})}$, \\ Danyella Vale Barros ${ }^{(d)}$ \\ (a) Departamento de História e Geografia, UEMA, ismayllirafael@gmail.com \\ (b)Professora Dr. Do Departamento de História e Geografia, UEMA, quesiaduartesilva@hotmail.com \\ (c)Departamento de História e Geografia, UEMA, estevaniacruz@gmail.com \\ (d)Departamento de História e Geografia, UEMA, danyellabarros-geo@hotmail.com
}

\section{Eixo: GEOGRAFIA FÍSICA E DESASTRES NATURAIS}

\section{Resumo}

\begin{abstract}
As enxurradas são fenômenos de natureza atmosférica, hidrológica ou oceanográfica que podem ocorrer em periodos chuvosos, é impotante destacar a relação da intensidade de precipitação atmosférica com a morfologia do terreno. Neste panorama, se faz necessário estudar a morfologia das vertentes e qual a relação nos fenômenos de enxurrada, tendo em vista que o alto curso da bacia hidrográfica do Anil encontra-se em uma região predominantemente urbana, tendo um numero de 50 (cinquenta) famílias atingidas pelas enxurradas, foram mapeados 8 (oito) áreas de incidência dos fenômenos de enxurrada. Neste sentido, é possível afirmar que esse número tende a ser maior, o qual é resultado da combinação de problemas sociais e ambientais.
\end{abstract}

Palavras chave:Vertentes; Enxurradas;alto curso da bacia hidrografica do Anil.

\section{Introdução}

As enxurradas são fenômenos de caráter hidrometeorológico ou hidrológico, ou seja, aqueles de natureza atmosférica, hidrológica ou oceanográficaque podem ocorrer em periodos chuvosos e são geralmente deflagradas por fortes chuvas rápidas ou até de longas durações. Sabe-se hoje que tais fenômenos estão relacionados com a quantidade e intensidade da precipitação atmosférica e também com a morfologia do terreno. Neste sentido, o presente trabalho visa relacionar a influência das vertentes nos fenômenos de enxurrada no alto curso da bacia hidrográfica do Anil no município de São Luís, apresentando uma breve exposição do conceito de desastre.

A ISDR (2009) considera desastre como uma grave mudança no funcionamento de uma comunidade ou de uma sociedade envolvendo perdas humanas, materiais, econômicas ou ambientais de grande extensão, em que os impactos superam a capacidade da comunidade ou da sociedade afetada de arcar com seus próprios recursos.

As vertentes são formas de relevo modeladas por processos internos e/ou externos, incluindo também a ação humana. Possui variadas formas como planar convexa, planar côncava, planar retilínea, convergente convexa, convergente côncava, convergente retilínea, divergente retilínea, divergente côncava e divergente convexa (VARLERIANO, 2008), que influenciam o fluxo ou o acúmulo de água 
e representam características fundamentais para ocorrência de desastres naturais, como os fenômenos de enxurrada. Dessa forma, para obter bons resultados no uso de vertentes, é necessário que haja uma descrição cuidadosa das suas formas para que seja possível estudar as implicações desse uso tanto a curto, quanto a longo prazo (ANJOS et.al, 2011).

Nesta perspectiva, Tominaga conceitua o fenômeno de enxurrada a seguir:

A enxurrada é definida como o "escoamento superficial concentrado e com alta energia de transporte, que pode ou não estar associado a áreas de domínio dos processos fluviais. É comum a ocorrência de enxurradas ao longo de vias implantadas sobre antigos cursos d'água com alto gradiente hidráulico e em terrenos com alta declividade natural"(TOMINAGA et.al 2009, p.42).

A magnitude das enxurradas ocorre devido à intensidade e distribuição das chuvas, tendo uma relação direta com a capacidade de infiltração do solo e a declividade do terreno, possuindo uma inter-relação com as características morfométricas e morfológicas de uma bacia hidrográfica. No meio natural, as vertentes apresentam um escoamento superficial das águas das chuvas lento, quando comparado com as vertentes em áreas urbanas, haja vista que o solo se apresenta impermeável, intensificado por alterações antrópicas.

De acordo com Marcelino (2008), a inclinação do terreno, ao favorecer o escoamento, contribui para intensificar a torrente e causar danos. Esse fenômeno costuma surpreender por sua violência e menor previsibilidade, exigindo uma monitorizarão complexa. O mesmo autor ainda destaca que as encostas reflorestadas protegem o solo, aumentam a infiltração das águas e a alimentação dos lençóis freáticos, reduzindo as enxurradas.

Neste sentido, as enxurradas são fenômenos que ocorrem de forma natural podendo ser agravados devido à interferência antrópica nos sistemas naturais. Quando esses processos atingem as populações geram danos, sejam eles diretos ou indiretos, podendo ser classificados como desastres.

\section{Metodologia}

Para alcançar os objetivos da pesquisa, foi necessário realizar pesquisas bibliográficas referentes ao estudo das vertentes e aos fenômenos de enxurradas, além de pesquisas cartográfica sobre a área de estudo; análise de imagens de satélite a partir do software Google Earth, objetivando o reconhecimento de possíveis áreas de ocorrência a enxurradas.

Foram visitadas diversas áreas durante o período chuvoso do ano de 2016 (primeiro semestre), num total de 6 (seis) trabalhos de campo e foram realizadas 18 (dezoito) entrevistas para identificação e comprovação das áreas de ocorrência dos eventos, sendo estas analisadas, descritas e registradas a partir de material fotográfico, com a utilização de câmera digital, e obtenção das coordenadas geográficas a partir de GPS. Foram elaboradas entrevistas semi-estruturadas, alicerçando-se em 
Marconi e Lakatos (2003) e Sá (2007), com adaptações relacionadas a área de estudo e aplicado aos moradores das áreas atingidas. Elaborou-se o mapa de Curvatura, baseado no processo de classificação de vertentes proposto por Valeriano et al. (2008), a partir do banco de dados cartográfico de Silva (2013),utilizando o software Arcgis for Desktop Advanced, versão 10.2, licença EFL999703439.Tais etapas objetivaram a compreensão do fenômeno no espaço geográfico.

\section{Resultados e Discussão}

A área de estudo da pesquisa corresponde ao alto curso da bacia hidrográfica do Anil, possuindo uma área de 5,25 km², abrangendo os bairros de João de Deus, Vila Lobão, Pirapora, Canaã, entre outros, pertencentes ao município de São Luís. Esta bacia está situada entre as coordenadas $2^{\circ} 33^{\prime} 0$ ”de latitude sul e de $44^{\circ} 15^{\prime} 29^{\prime \prime}$ longitude oeste.

A análise de vertente justifica-se por entendê-la como elemento dominante do relevo e categoria central na sua dinâmica processual (CASSETI, 1995). O autor destaca ainda que nas vertentes se materializam as relações de apropriação da natureza pelo homem.

$\mathrm{Na}$ pesquisa em questão foram mapeados 6 (seis) tipos de formas de vertentes a partir da classificação de Valeriano (2008), sendo elas: Planar Convexa, Planar Côncava, Convergente Convexa, Divergente Retilínea, Divergente Côncava e Divergente Convexa (Figura 1). 

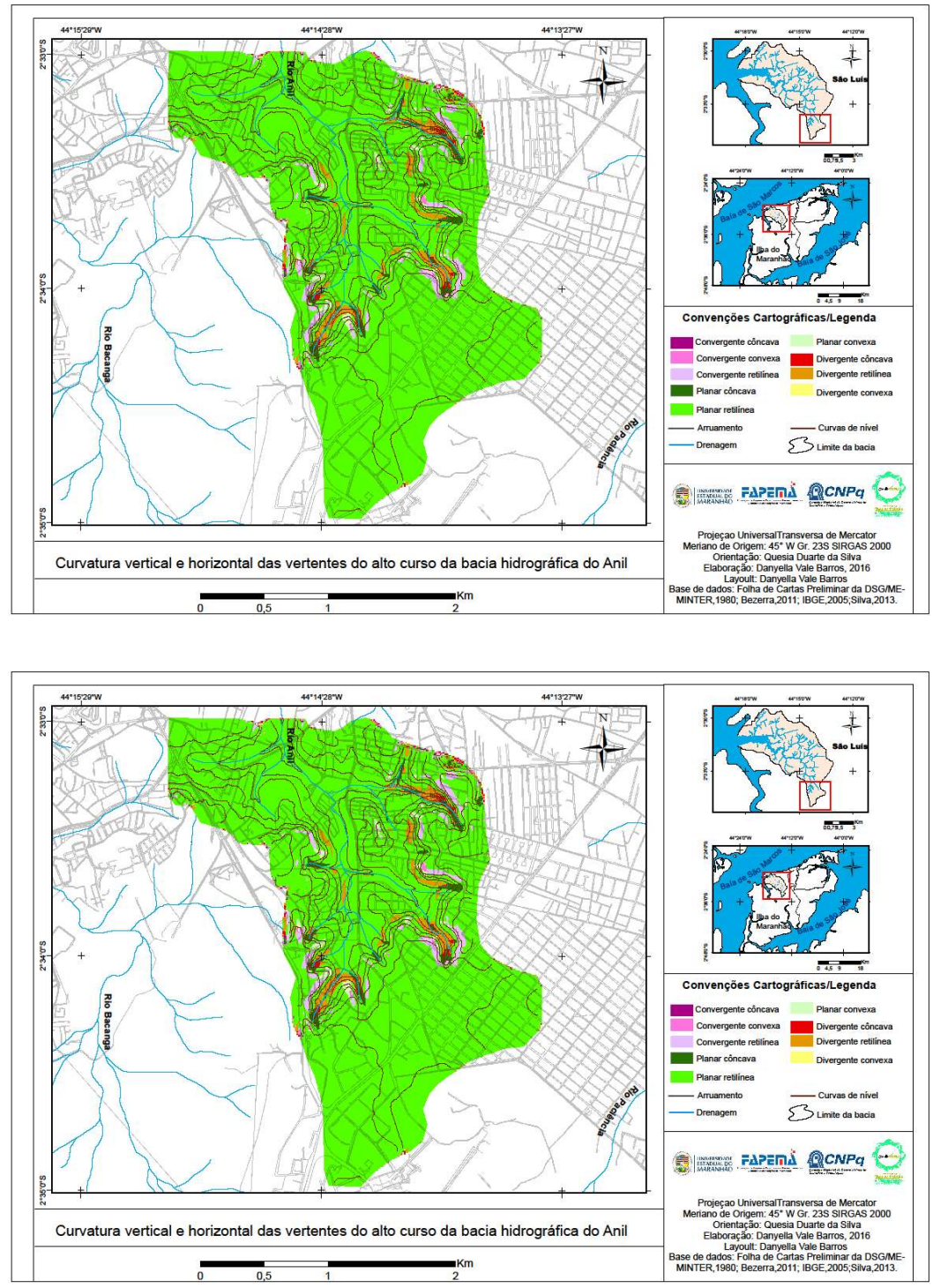

Figura 1 Curvatura vertical e horizontal do alto curso da bacia hidrográfica do Anil Fonte: Barros, 2016

As vertentes possuem formas que indicam a direção do fluxo das águas superficiais. Na área de estudo, as vertentes do tipo côncavas somam o total de $0,95 \%$ do valor da área de estudo e é comum neste tipo de vertente a ocorrência de processos erosivos e a tendência à concentração do escoamento superficial, potencializando o transporte de detritos.

Observou-sena rua do Sol no bairro da Vila lobão, aocorrênciado fenômeno de enxurrada, já que a rua possui $30 \%$ de inclinação favorecendo o surgimento do fenômeno, associando ao escoamento superficial que ocorre nos períodos chuvosos, resultando no transporte de sedimentos que se configuram devido à retirada da cobertura vegetal (Figura $4 \mathrm{a} \mathrm{e} 4 \mathrm{~b}$ ). 

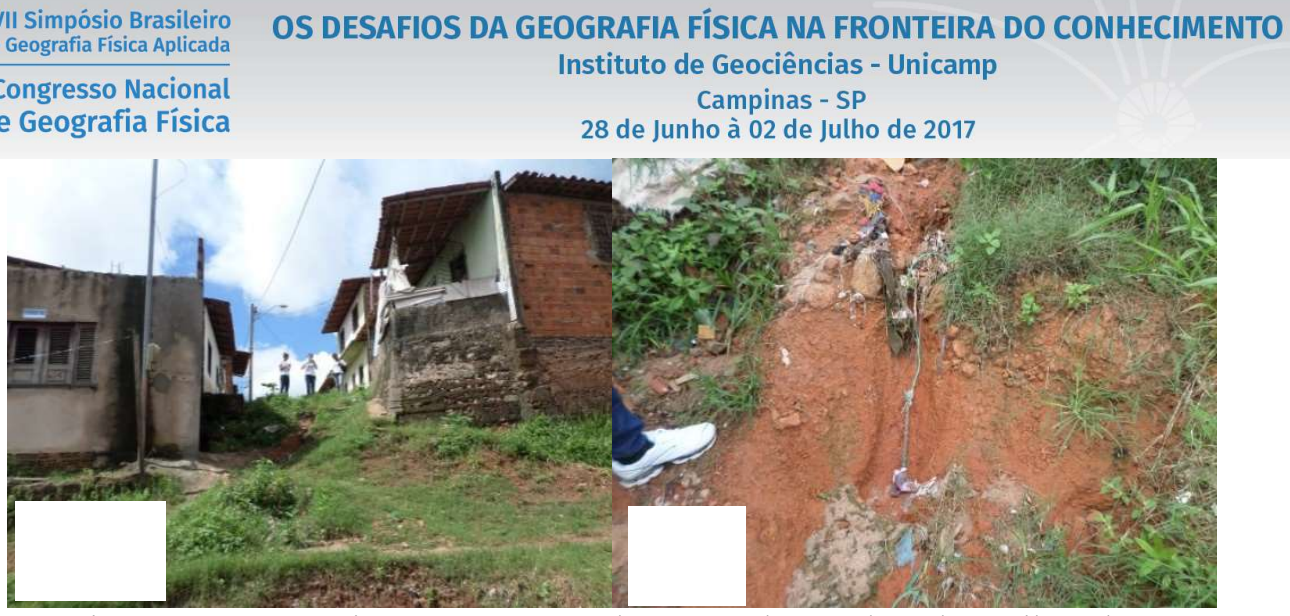

Figra 2a - Vertente tipo côncava,pontode enxurrada, rua do Sol na Vila Lobão

Figra $2 \mathrm{~b}$ - Processo ersosivo, $\mathrm{n}$ o terço superior da vertente

Fonte: Própria pesquisa, 2016.

Conforme a tabela 1 , cerca de $97,5 \%$ da área da bacia é abrangida por vertentes do tipo convexa, apresentando como principal característica, a dispersão das água. Caso fosse côncava, provavelmente os fenômenos de enxurradas seriam ainda mais agressivo.

Vale destacar, que as vertentes encontradas em áreas urbanas devido ao processo de urbanização tem sua forma original alterada, por obras de engenharia, possuindo relação direta no fluxo do escoamento superficial.

Tabela1 - Formas das vertentes do alto curso da bacia hidrográfica do Anil

\begin{tabular}{c|c|c}
\hline Formas de vertentes & Valor Absoluto $\left(\mathrm{Km}^{2}\right)$ & Valor Relativo \% \\
\hline Convergente côncava & 00,0 & 0 \\
\hline Convergente retilínea & 00,0 & 0 \\
\hline Convergente convexa & 0,13 & 2,49 \\
\hline Planar côncava & 0,01 & 0,19 \\
\hline Planar retilínea & 0,00 & 0 \\
\hline Planar convexa & 0,13 & 2,49 \\
\hline Divergente côncava & 0,04 & 0,76 \\
\hline Divergente retilínea & 0,08 & 1,53 \\
\hline Divergente convexa & 0,83 & 92,52 \\
\hline Total & & $\mathbf{9 9 , 9 8}$ \\
\hline
\end{tabular}

Fonte: Própria pesquisa, 2016.

\section{$4 \quad$ Considerações finais}

Durante os trabalhos de campo realizados no alto curso da bacia hidrográfica do Anil, foi possível analisar as formas de vertentes presente na área de objeto de estudo associando a ocorrência dos fenômenos de enxurrada. No alto curso foram mapeados 8 (oito) locais com incidência de enxurradas, 
com base nas entrevistas aplicadas identificou-se o número de 50 (cinquenta) famílias afetadas. De acordo com a pesquisa, é possível afirmar que esse número tende a ser maior, o qual é resultado da combinação de problemas sociais e ambientais.

\section{REFERENCIAS}

ANJOS, D. S. JUNIOR M. M. Nunes J. O. R. Classificação da curvatura de vertentes em perfil via Modelo numérico de Terreno.Anais XV Simpósio Brasileiro de Sensoriamento Remoto - SBSR, Curitiba, PR, Brasil, 30 de abril a 05 de maio de 2011, INPE p.2286.

CASSETI, V. Ambiente e apropriação do relevo. 2. ed. São Paulo: Contexto, 1995.

ISDR. Sobre Reduccióndelriesgo de desastres. - InternationalStrategy for DisasterReduction. Suiza: Naciones Unidas, 2009. Disponível em: http://www.unisdr.org/Publications. Acesso em: 25 de Janeiro de 2017.

MARCELINO, E. V. Desastres naturais e geotecnologias: conceitos básicos. Santa Maria: CRS/INPE, 2008.

TOMINAGA, L. K. SANTORO J. AMARAL R. Desastres naturais Conhecer para prevenir. instituto Geológico Secretaria do Meio Ambiente Governo do Estado de São Paulo. 1ª edição São Paulo 2009. 